Thorax (1973), 28, 644.

\title{
Pulmonary arterial aneurysm ${ }^{1}$
}

\author{
ERIK TRELL \\ Department of Medicine, University of Lund, Malmö General Hospital, Malmö, Sweden
}

Trell, E. (1973). Thorax, 28, 644-649. Pulmonary arterial aneurysm. This is the case report of the clinical, radiographic, and physiological progress of a patient with increasing aneurysmal dilatation of the main pulmonary arteries, followed over a period of 10 years.

Dilatation of the main pulmonary arteries (Greene et al., 1949; Liu, Jona, and Haring, 1958; Warembourg et al., 1968) and pulmonary arterial aneurysms (Hughes and Stovin, 1959; Nair, 1964; Higuchi, Kitamura, and Terada, 1969; Ravines, 1960; Levy, 1961; Best, 1967) may occur in a wide variety of cardiopulmonary and inflammatory diseases, usually in association with pulmonary hypertension. Pronounced central pulmonary arterial aneurysm formation can also occur as an isolated malformation. External stigmata of Marfan's syndrome (Nair, 1964; Best, 1967; McKusick, 1955) and/or cystic medionecrosis of the pulmonary arterial vessel wall (Levy, 1961; Best, 1967; McKusick, 1955; Kapanci, 1965; Natelson, Watts, and Fred, 1970) are often noted in such cases. Pulmonary hypertension (Natelson et al., 1970) with dissection and rupture (Natelson et al., 1970; Thomas, 1971) may be associated features.

'Congenital idiopathic dilatation of the pulmonary arteries' may appear to represent another variety of arterial widening. So far, the majority of reported examples of this disorder are in adolescents or adults, but the presumed congenital nature is supported by its occurrence in children (Greene et al., 1949 ; Goetz and Nellen, 1953 ; Kaplan, Schlichter, Graham, and Miller, 1953; Balboni and Lopresti, 1961; Dreyfus and Morin, 1963; Taussig, 1947; Placák and Jech, 1971). Usually, it is a benign and symptomless condition in which the upper part of the common main pulmonary artery and the origin of the right and left main pulmonary arteries are mainly affected (Warembourg et al., 1968; Balboni and Lopresti, 1961; Dreyfus and Morin, 1963). However, there are cases on record with pulmonary hypertension

JThis study was supported by the Swedish National Association against Heart and Chest Diseases and the Hulda Almroth Foundation
(Evans, 1951; Bulgarelli and Alzona, 1955; Turano and Gambaccini, 1958), associated Marfan's syndrome (McKusick, 1955; Balboni and Lopresti, 1961), cystic medionecrosis of the pulmonary arterial wall (Dreyfus and Morin, 1963), and pronounced general widening of the entire length of both main pulmonary arteries (Turano and Gambaccini, 1958; Taussig, 1947), even with bronchial compression (Taussig, 1947). Imperfect division of the common trunk with 'grosse pulmonairepetite aorte' (Laubry, Routier, and Heim de Balsac, 1940) has been suggested as the pathogenetic mechanism of congenital idiopathic dilatation of the pulmonary artery, but as yet this idea has found little support (Balboni and Lopresti, 1961). 'Weakness of the wall of the pulmonary artery' has been favoured as the cause of the disease in keeping with the concept of medial deficiency in more severe, general or saccular pulmonary arterial aneurysm formation (Balboni and Lopresti, 1961; Dreyfus and Morin, 1963; Befeler, MacLeod, Baum, and Schwartz, 1967). Furthermore, few cases of idiopathic dilatation of the pulmonary artery have been reported in patients over 60 years of age (Greene et al., 1949).

It has been stated that knowledge of the longterm outcome of the disorder is not well established, and that severe pulmonary vascular disease may eventually occur (Kaplan et al., 1953; Turano and Gambaccini, 1958; Dreyfus and Morin, 1963). It appears possible, therefore, that congenital idiopathic dilatation of the pulmonary arteries and more pronounced pulmonary arterial aneurysm formation may represent modalities of closely related or identical disease processes. The purpose of the present paper is to report a long-term study on an unusually old patient whose clinical progress provides further information with regard to the natural history of pulmonary arterial aneurysm and its possible effects on living function. 


\section{CASE REPORT}

The patient was a woman born in 1898. Her early development was normal and routine medical examinations during childhood and adolescence were negative. She had had no venereal diseases, and had had a normal pregnancy in 1919. In 1946, without preceding illness, she first noted slight dyspnoea on effort and intermittent ankle oedema. At about the same time she became aware of a pulsating bulge in the left pectoral area. This slowly increased in size during the ensuing years, while the other symptoms remained unchanged. After an upper respiratory tract
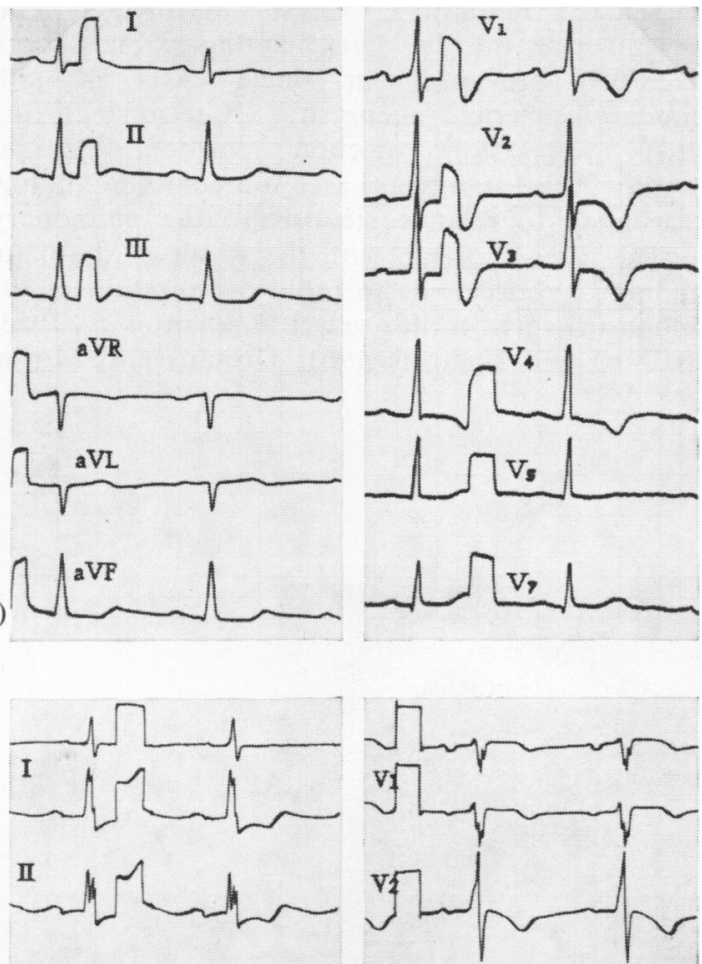

III

(b)
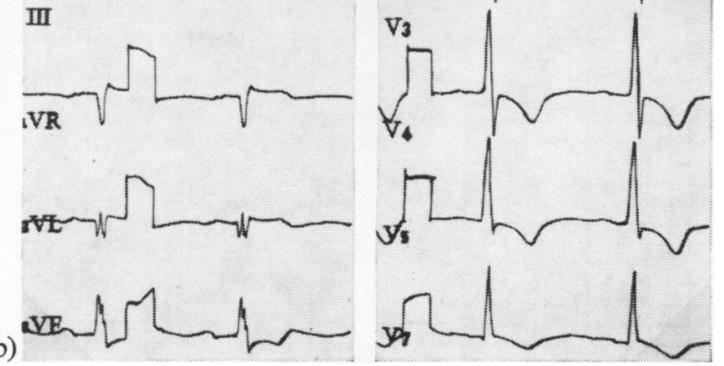

FIG. 1. Electrocardiographic findings: (a) 1961—right ventricular hypertrophy and strain; (b) 1971-biventricular strain and possible biventricular hypertrophy with left ventricular preponderance.
T A B L E I

LUNG FUNCTION

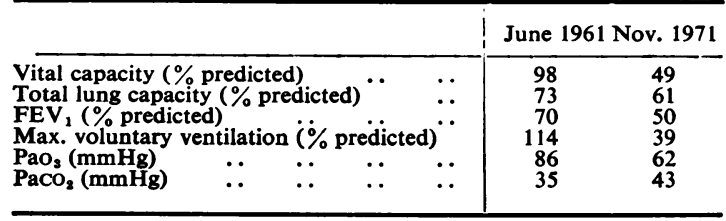

infection in November 1960, exertional dyspnoea increased, and she sought medical advice. The chest radiograph showed a 'left-sided mediastinal mass', and tomography revealed backward dislocation of the lower trachea and main bronchi.

The patient was admitted to hospital in June 1961 for further investigation. The physical findings included a short systolic murmur with maximum intensity over the apex, a parasystolic and a very soft diastolic murmur along the left sternal border, and an accentuated second pulmonary sound. The blood pressure was $150 / 105 \mathrm{mmHg}$. The WR was negative, and the rheumatoid factors were normal. Lung function tests are shown in Table I. The electrocardiogram indicated right ventricular hypertrophy and strain (Fig. 1a). Cardiac catheterization demonstrated moderate pulmonary arterial hypertension (Table II). The chest radiograph showed enlargement of the right heart, very wide central pulmonary arteries, and over the left hilum a fist-sized mass dislocating the oesophagus, the trachea, and the main bronchi posteriorly (Fig. 2a). Aneurysmal pulmonary arterial dilatation was suspected and verified by angiography (Fig. 3). The patient was discharged on digitalis and an intermittent diuretic regime, which she has since maintained.

Cardiological re-investigation was performed in November 1971. The patient was still in a reasonably satisfactory condition, although effort dyspnoea had slowly progressed so that she was unable to climb the stairs. She had not experienced palpitations, angina of effort, or syncopal attacks but was aware of moderate intermittent ankle swelling. She was tachypnoeic at rest and had mild orthopnoea and ankle oedema. There was peripheral and slight central cyanosis but no clubbing. There were no features of Marfan's syndrome. There was no venous congestion nor hepatomegaly. A pulsating swelling was present over the upper part of the anterior chest wall on the left side. A systolic thrill could be felt over the entire precordium. A medium-pitched systolic murmur with maximum intensity, grade $3 / 6$, was heard substernally at the level of the third costal interspace with radiation to the right of the sternum and to the left axilla; a faint high-pitched diastolic murmur was also noted in the same area. The pulmonary component of the second heart sound was loud. BP $140 / 100 \mathrm{mmHg}$. Detailed laboratory analyses including urinary aminoacid determinations, hepatic function, and haematological studies, Coomb's test, and plasma electrophoresis were unremarkable. The chest radiograph 
T A B LE I I

HEART CATHETERIZATION FINDINGS, 1961 AND 1971

\begin{tabular}{|c|c|c|c|c|c|c|c|c|c|c|c|c|}
\hline & \multicolumn{3}{|c|}{$\underset{\text { (mmHg) }}{\text { Right Atrium }}$} & \multicolumn{3}{|c|}{$\underset{(\mathrm{mmHg})}{\text { Right }}$ Ventricle } & \multicolumn{3}{|c|}{$\underset{(\mathrm{mmHg})}{\text { Pulmonary Artery }}$} & \multirow{2}{*}{$\frac{\begin{array}{c}\text { PCP } \\
(\mathrm{mmHg})\end{array}}{\mathrm{m}}$} & \multirow{2}{*}{$\begin{array}{l}\text { Cardiac Output } \\
(1 / \mathrm{min})\end{array}$} & \multirow[t]{2}{*}{$\begin{array}{l}\text { Left-to-Right } \\
\text { Shunt }\end{array}$} \\
\hline & $' a$ ' & 'v' & $\mathrm{m}$ & $\mathbf{S}$ & id & $\overline{\text { ed }}$ & $\mathbf{S}$ & D & $\mathrm{m}$ & & & \\
\hline $\begin{array}{l}\text { June } 1961 \\
\text { Nov. } 1971\end{array}$ & $\begin{array}{r}14 \\
7\end{array}$ & $\begin{array}{l}8 \\
3\end{array}$ & $\begin{array}{l}7 \\
1\end{array}$ & $\begin{array}{l}60 \\
52\end{array}$ & $\begin{array}{r}-1 \\
2\end{array}$ & $\begin{array}{l}7 \\
7\end{array}$ & $\begin{array}{l}50 \\
48\end{array}$ & $\begin{array}{l}25 \\
25\end{array}$ & $\begin{array}{l}35 \\
34\end{array}$ & - & $4 \cdot 6$ & $\begin{array}{l}\text { nil } \\
\text { nil }\end{array}$ \\
\hline
\end{tabular}

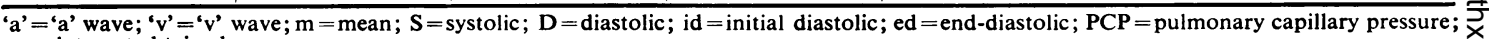
$\underline{\mathrm{a}}=$ data not obtained.

showed an enormous increase in size of the central pulmonary arteries with possible saccular aneurysms but sparse peripheral vasculature (Fig. 2b). Lung function tests revealed a restrictive defect (see Table I). The electrocardiogram had changed considerably: the right ventricular preponderance had disappeared and there were signs of left ventricular strain (Fig. 1b). Cardiac catheterization revealed persistent, moderate pulmonary hypertension with no evidence of shunting or of pulmonary or tricuspid valvular lesions (Table II). Satisfactory pulmonary capillary pressures could not be obtained, and angiocardiography was not performed according to the patient's wishes.
PHYSICAL FINDINGS Chest assymetry with $\stackrel{+}{\stackrel{+}{+}}$ prominence of the left hemithorax has been $\vec{c}$ recorded previously in single cases of pul- $\mathbb{D}$ monary arterial aneurysm (Natelson et al., $\underset{\mathbb{D}}{\stackrel{\vec{D}}{0}}$ 1970). A systolic ejection murmur with in- $\frac{\mathbb{J}}{3}$ tensity in the pulmonary area is a common finding, $\mathbb{\Phi}$ attributed to relative stenosis of the pulmonary $\overrightarrow{\vec{Q}}$ orifice in comparison with the width of the main pulmonary artery, or to rapid deceleration of the blood delivered to this vessel (Kaplan et al., 1953; Balboni and Lopresti, 1961; Dreyfus and Morin, 
FIG. 2. P-A chest radiograph: (a) 1961-very wide pulmonary arterial segment and aneurysmal dilatation of the right main pulmonary artery. Sparse peripheral pulmonary vasculature; (b) 1971-enormously dilated central pulmonary arteries. Note suspect saccular lateral extension of the right main pulmonary artery. Sparse peripheral pulmonary vasculature; no pulmonary parenchymatous changes. Slight deviation of the trachea and oesophagus.

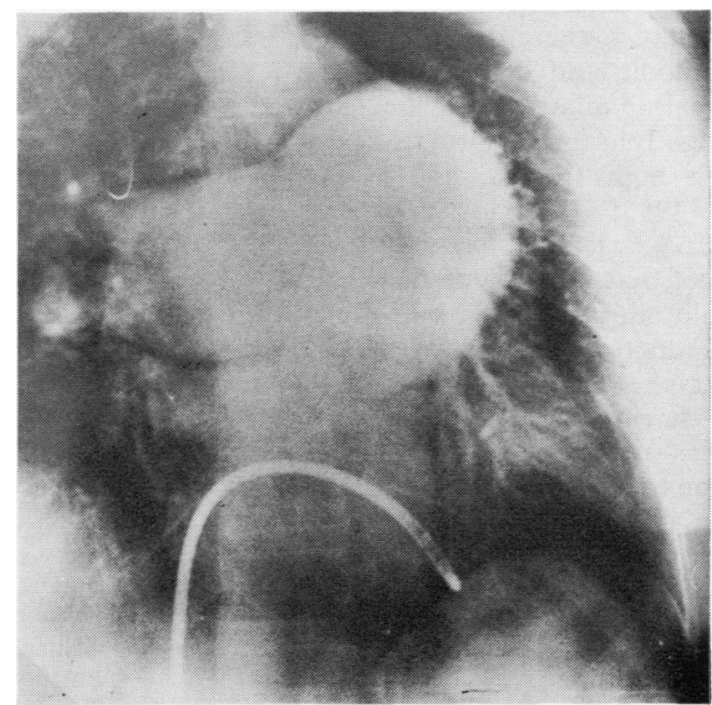

FIG. 3. Right ventriculography (1961). Enormous dilatation of both main pulmonary arteries, and very narrow peripheral pulmonary arteries with delayed and scanty contrast filling. 
1963). A systolic thrill has also been noted (Kaplan et al., 1953). Accentuation of the pulmonary second sound is often heard and may be due to the closeness of the dilated pulmonary artery to the chest wall rather than to pulmonary hypertension (Balboni and Lopresti, 1961; Papaionnou, Agustsson, and Gasul, 1961). Diastolic murmurs are infrequent but have been recorded in one patient with pulmonary hypertension (Natelson et al., 1970). In the present patient, there were no signs of coexisting aortic or pulmonary incompetence, persisting ductus arteriosus or pulmonary arteriovenous fistula to account for the diastolic murmur which could be best heard over the central pulmonary arteries.

PULMONARY HYPERTENSION Severe pulmonary hypertension has been reported in pulmonary arterial aneurysm with persistent ductus arteriosus (Ravines, 1960; McKusick, 1955) and in patients with very wide pulmonary arteries due to cystic medionecrosis (Natelson et al., 1970). In the present patient, in whom pulmonary hypertension was moderate, peripheral lung arteries were narrow, although peripheral stenoses were not observed (Fig. 3). Pulmonary arterial aneurysm and peripheral stenoses of the pulmonary arteries may sometimes co-exist (Bugaro, dalla Volta, and de Castro, 1955) when pulmonary hypertension is a likely occurrence. However, in a recent case report of cystic medionecrosis, pulmonary arterial aneurysm, and pulmonary hypertension it was stated that the relation between these conditions remains unclear (Natelson et al., 1970). It is of interest, therefore, that sometimes patients in the middle and higher age groups with congenital idiopathic dilatation of the pulmonary artery have slightly raised (Dreyfus and Morin, 1963) to very high (Evans, 1951; Bulgarelli and Alzona, 1955; Turano and Gambaccini, 1958) pulmonary arterial pressures. It seems reasonable to expect that in the presence of very dilated central pulmonary arteries with a more or less abrupt reduction in diameter between them and their peripheral branches, abnormalities of pulmonary haemodynamics may occur. Another possibility was mentioned by Evans (1951), who related pulmonary hypertension in congenital dilatation of the pulmonary artery to the development of endarteritis fibrosa in the pulmonary circulation. Chronic hypoxia is a wellknown cause of pulmonary hypertension and might be considered in the present case. Surprisingly, however, her pulmonary arterial pressure had not increased since 1961 .
NATURAL HISTORY The increase in size of the main $\frac{\overline{ }}{\overline{0}}$ pulmonary arteries over the 10 -year period indi- $\frac{\sigma}{\bar{\phi}}$ cates that the lesion can be progressive. The $\propto$ increase in effort dyspnoea and the development is of a restrictive impairment of ventilatory capacity $\overrightarrow{0}$ may be due in part to left ventricular strain and in part to the space-occupying effect of the $\vec{\omega}$ expanding pulmonary arteries. Recent studies have drawn attention to the occurrence of left ven- $\vec{x}$ tricular failure in various types of pulmonary disorder (Rao, Cohn, Eldridge, and Hancock, 1968).

\section{REFERENCES}

Balboni, F. A., and Lopresti, J. (1961). Congenital idiopathic dilatation of the pulmonary artery in children. A report of seven cases. Bulletin of the St. Francis Hospital and $\frac{\mathbb{D}}{3}$ Sanatorium, 17, 1.

Befeler, B., MacLeod, C. A., Baum, G. L., and Schwartz, H. (1967). Idiopathic dilatation of the pulmonary artery. American Journal of Medical Science, 254, 667.

Best, J. (1967). Dissecting aneurysm of the pulmonary artery with multiple cardiovascular abnormalities and pulmonary hypertension. Medical Journal of Australia, 2, 1129.

Bugaro, L., dalla Volta, S., and de Castro, B. (1955). Le cathétérisme cardiaque dans la dilatation idiopathique de l'artère pulmonaire. Archives des Maladies du Coeur et des Vaisseaux, 48, 721.

Bulgarelli, R., and Alzona, L. (1955). La dilatazione congenita isolata dell'arteria polmonare. Minerva Pediatrica, 7, 591.

Dreyfus, P., and Morin, B. (1963). La dilatation isolée de l'artère pulmonaire. Coeur et Médecine Interne, 2, 145.

Evans, W. (1951). Congenital pulmonary hypertension. Proceedings of the Royal Society of Medicine, 44, 600.

Goetz, R. H., and Nellen, M. (1953). Idiopathic dilatation of the pulmonary artery. South African Medical Journal, 27, 360 .

Greene, D. G., de Forest Baldwin, E., Sterling Baldwin, J.. 3 Himmelstein, A., Roh, C. E., and Cournand, A. (1949). Pure congenital pulmonary stenosis and idiopathic congenital dilatation of the pulmonary artery. American $D$ Journal of Medicine, 6, 24.

Higuchi, M., Kitamura, S., and Terada, I. (1969). An autopsy case of multiple intrapulmonary artery aneur- o ysms with systemic thromboendophlebitis, the "Hughes- $N$ Stovin syndrome". Acta Pathologica Japonica, 19, 69.

Hughes, J. P., and Stovin, P. G. I. (1959). Segmental pulmonary artery aneurysms with peripheral venous $\underset{C}{\sigma}$ thrombosis. British Journal of Diseases of the Chest, $53,19$.

Kapanci, Y. (1965). Médionécrose et anévrysmes disséquants des artères intrapulmonaires. Description d'un cas chez le nourisson et étude morphogénétique de la To médionécrose type GSELL-ERDHEIM. Frankfurter Zeitschrift für Pathologie, 74, 425.

Kaplan, B. M., Schlichter, J. G., Graham, G., and Miller, $\mathbb{D}$ G. (1953). Idiopathic congenital dilatation of the pulmonary artery. Journal of Laboratory and Clinical Medicine, 41, 697. 
Laubry, C., Routier, D., and Heim de Balsac, R. (1940). Grosse pulmonaire. Petite aorte. Affection congénitale. Bulletin et Mémoires de la Société Médicale des Hôpitaux de Paris, 56, 847.

Levy, H. (1961). Partial rupture of pulmonary artery with lesions of medionecrosis in a case of mitral stenosis. American Heart Journal, 62, 31.

Liu, C. K., Jona, E., and Haring, O. M. (1958). The large pulmonary artery. Angiology, 9, 67.

McKusick, V. A. (1955). The cardiovascular aspects of Marfan's syndrome: a heritable disorder of connective tissue. Circulation, 11, 321.

Nair, D. V. (1964). Aneurysmal dilation of pulmonary artery. Review of literature and report of a case. British Journal of Clinical Practice, 18, 217.

Natelson, E. A., Watts, H. D., and Fred, H. L. (1970). Cystic medionecrosis of the pulmonary arteries. Chest, 57, 333.

Papaionnou, A. C., Agustsson, M. H., and Gasul, B. M. (1961). Early manifestations of the cardiovascular disorders in Marfan syndrome. Pediatrics, 27, 255.

Placák, B., and Jech, J. (1971). Aneurysm of the pulmonary artery. International Surgery, 55, 343.
Rao, B. S., Cohn, K. E., Eldridge, F. L., and Hancock, E. W. (1968). Left ventricular failure secondary to chronic pulmonary disease. American Journal of Medicine, 45, 229.

Ravines, H. T. (1960). Dissecting hematomas of intrapulmonary arteries in a case of pulmonary hypertension associated with patent ductus arteriosus. Journal of Thoracic and Cardiovascular Surgery, 39, 760.

Taussig, H. B. (1947). In Congenital Malformations of the Heart, p. 377. The Commonwealth Fund, New York.

Thomas, T. V. (1971). Aneurysm of the pulmonary artery. Postgraduate Medicine, 49, 65.

Turano, L., and Gambaccini, P. (1958). Anatomical and roentgenological aspects of the solitary s.c. idiopathic dilatation of the pulmonary artery (with some remarks regarding its pathogenesis). Scientia Medica Italica, 6,435 .

Warembourg, H., Pauchant, M., Ducloux, G., Bertrand, M., and Delbecque, H. (1968). La dilatation idiopathique de l'artère pulmonaire. A propos de 14 cas. Lille Médical, 13, 962. 